\title{
The Relationship Between Bound Water and Carbohydrate Reserves in Association with Cellular Integrity in Fragaria vesca Stored Under Different Conditions
}

\author{
María Blanch • María T. Sanchez-Ballesta • \\ María I. Escribano • Carmen Merodio
}

Received: 7 February 2014 / Accepted: 25 November 2014 / Published online: 15 December 2014

(C) The Author(s) 2014. This article is published with open access at Springerlink.com

\begin{abstract}
It has been recognized that high $\mathrm{CO}_{2}$ concentrations maintain the freshness of strawberries, reducing weight loss and the incidence of decay. Since strawberries have high tolerance threshold to $\mathrm{CO}_{2}$, it is of interest to know what changes occur in cellular water distribution when the threshold is reached or exceeded. Moreover, as strawberries are prone to producing exudate during storage at low temperatures, application of technologies improving water retention is needed. Changes in bound water content were analyzed in relation to simple sugars, polyols, and fructooligosaccharides (FOS) in Fragaria vesca stored at low temperature $\left(0^{\circ} \mathrm{C}\right)$ in the presence of 0,20 , or $40 \% \mathrm{CO}_{2}$. Fruits were analyzed at the end of a 3day treatment and after transfer to air for one additional day. Unfavorable storage conditions were associated with a decrease in the levels of bound water and in that of 1-kestose and myoinositol. However, the 1-kestose and myo-inositol content was enhanced when $40 \% \mathrm{CO}_{2}$-treated strawberries were transferred to air at the same time as an increase in bound water content and a restoration of intracellular water took place. The ability of the fruit to modulate the accumulation of these compounds, and by extension their water binding strength, in conjunction with the pool of the bound water fraction, appears to be a mechanism associated with the maintenance of cellular structural integrity. Variation in the percentage of air space and in the weight loss rate produced by enhancing the $\mathrm{CO}_{2}$ treatment during storage at $0{ }^{\circ} \mathrm{C}$ was also analyzed.
\end{abstract}

Keywords Strawberry $\cdot$ High $\mathrm{CO}_{2} \cdot$ Fructooligosaccharides · Bound water $\cdot$ Air space $\cdot$ myo-inositol

M. Blanch • M. T. Sanchez-Ballesta • M. I. Escribano

C. Merodio $(\square)$

Department of Characterization, Quality and Security, Institute of

Food Science Technology and Nutrition (ICTAN-CSIC), Jose

Antonio Novais 10, Madrid 28040, Spain

e-mail: merodio@ictan.csic.es

\section{Introduction}

Water is the most abundant molecule in fruit and, especially in strawberries, it has a high impact on its quality and storability. The fact that only about $10 \%$ of the solid matter in strawberries has to cope with a larger amount of liquid could explain, in part, their high perishability and susceptibility to textural damage, fungal decay, and liquid leakage. Moreover, changes in fruit water status regulate ripening processes to some extent (Frenkel and Hartman 2012) and modifications in the content of the different water fractions have been reported (Goñi et al. 2007). Changes in the bound water fraction are at least partially the result of modifications in the levels of hydrophilic molecules with high water-binding capacity. It was reported that the bound water that represents unfreezable water (Wolfe et al. 2002) plays an important role in tolerance to different environmental stresses, such as freezing and drought (Rascio et al. 1998; Sun 2000). Indeed, fruit stored at low temperature under adequate high $\mathrm{CO}_{2}$ concentrations had a larger bound water fraction (Goñi et al. 2011), in association with an increase of inulin series fructans, which consist of linear $\beta$ (2-1) linked fructose residues with a terminal glucose residue (Blanch et al. 2011). Fructans have been increasingly recognized as protective agents in stress environments (Valluru and Van den Ende 2008). In addition to their protective influence on cell structures, fructooligosaccharides (FOS) participate in carbon storage. Consequently, variations in the levels of sucrose, glucose, and fructose are thought to be linked to the changes in FOS. Sugar alcohols, or polyols, are also closely associated with hexose metabolism, and they act as compatible solutes in response to salt and drought stress, playing multiple roles in plant protection (Williamson et al. 2002; Merchant and Richter 2011). However, the mechanism by which polyhydroxyalcohols could protect fruits under changing environmental conditions is less well understood. 
The benefits of short-term high $\mathrm{CO}_{2}$ treatment in maintaining freshness, reducing water loss, and on the incidence of decay has long been recognized in highly perishable fruits (Sanchez-Ballesta et al. 2006; Wang et al. 2014). However, when $\mathrm{CO}_{2}$ concentrations exceed the tolerance threshold, they can also be harmful. Development of off-flavors is a well-known common detrimental effect caused by the accumulation of fermentative metabolites, especially when high $\mathrm{CO}_{2}$ concentrations are combined with reduced oxygen levels. Therefore, it would be useful to identify the principal metabolic markers indicative of fruit damage associated with excessive $\mathrm{CO}_{2}$ levels. Furthermore, by taking advantage of the tolerance of strawberries to high $\mathrm{CO}_{2}$ levels, benefits can be obtained if the detrimental effect can be mitigated after transfer to ambient $\mathrm{CO}_{2}$. Moreover, as strawberries are prone to producing exudate during storage at low temperatures, the application of techniques to improve cellular water retention is useful.

The aim of the present work was to analyze how changes in bound water fractions were correlated with carbohydrate reserves and cell structure in strawberry fruit stored under different conditions. Accordingly, Mara des Bois strawberries (Fragaria vesca) were stored at low temperature $\left(0^{\circ} \mathrm{C}\right)$ and treated with different $\mathrm{CO}_{2}$ concentrations $(0,20$ and, $40 \%)$. The bound water fraction, simple sugars, short-chain FOS, and polyols were analyzed at the end of the $\mathrm{CO}_{2}$ treatment and after the strawberries had been transferred to air for an additional day. A thermal analysis of the aqueous solutions of various polyols (mannitol, sorbitol, and myo-inositol) was performed, and the contribution of high $\mathrm{CO}_{2}$ concentrations to weight loss, intercellular air space, and cellular tissue integrity were also determined.

\section{Materials and Methods}

\section{Plant Material}

The organic strawberries used in this study (Fragaria vesca $\mathrm{L}$. cv. Mara des Bois) were grown in an orchard in San Sebastian de los Reyes (Madrid, Spain), whose coordinates are $40^{\circ} 32^{\prime} 49^{\prime \prime} \mathrm{N}, 3^{\circ} 37^{\prime} 33^{\prime \prime}$ W. Strawberries belonging to various inflorescences were harvested, immediately ( $2 \mathrm{~h})$ transported to the Institute of Food Science Technology and Nutrition, and selected for uniform size and color. The strawberries with $8.9 \%$ total soluble solids as ${ }^{\circ}$ Brix, $0.7 \%$ titratable acidity, and with an external $L \times 18, a \times 38, b \times 28$ color were randomly divided into three groups and stored at $0{ }^{\circ} \mathrm{C}( \pm 0.5)$ and $>95 \%$ RH in three $1 \mathrm{~m}^{3}$ containers. Fifteen plastic boxes containing approximately $0.4 \mathrm{~kg}$ of strawberries per box were weighed and placed into storage containers. Fruits were flushed continuously for 3 days with increasing amounts of $\mathrm{CO}_{2}(0,20$, and $40 \%)$. Prior to introducing the fruit into the container, it was exposed to a stronger gas flow until the gas composition at the exit has reached the prefixed value. Each treatment was introduced through a connector at the top of the container. The gas exit was placed at the lower opposite end of the container where the gas composition was measured twice daily using a Check Mate $9900 \mathrm{O}_{2}, \mathrm{O}_{2} / \mathrm{CO}_{2}$ headspace analyzer (Dansensor España, S.L.U.). The three treatments were performed with $\mathrm{CO}_{2}$ concentrations of 0.03 (normal air gas composition), 20, or $40 \%$. For all treatments, the $\mathrm{O}_{2}$ concentration was maintained constant at $20 \%$, adjusting the $\mathrm{N}_{2}$ concentration accordingly. The humidified gas flow was kept constant at $100 \mathrm{~mL} / \mathrm{min}$ until the end of the experiment. After 3 days at each concentration of $\mathrm{CO}_{2}$, strawberries were removed, weighed, and transferred to a similar container and fluxed continuously with humidified air for one additional day, under the same conditions of temperature and humidity $\left(0{ }^{\circ} \mathrm{C}\right.$ and $95 \% \mathrm{RH})$. Initially, at the end of the 3-day sampling period and 1 day after exposure to air, 45 strawberries were assessed for quality, while another 45 were removed at random from each of the treatment groups and divided into three batches of 15 berries. The 15 strawberries from each batch were used as biological replicates and each replicate was mixed, frozen in liquid nitrogen, and stored at $-80{ }^{\circ} \mathrm{C}$ for further analysis.

Extraction and Chromatographic Determination of Glucose, Fructose, Sucrose and Polyols

Berry samples of approximately $3 \mathrm{~g}$ were homogenized in $5 \mathrm{~mL}$ of ultra-pure water and centrifuged at $30,000 \mathrm{~g}$ for $20 \mathrm{~min}$, and the supernatants were filtered through a $0.45-\mu \mathrm{m}$ pore size membrane. Sugars and polyols were determined by HPAEC-PAD with a Metrosep Carb 1250 IC column $(4.6 \times 250 \mathrm{~mm})$. Samples were analyzed on an Ion Chromatography 817 Bioscan (Metrohm, Herisau, Switzerland) system equipped with a pulsed amperometric detector (PAD) and a gold electrode. Isocratic elution was carried out with $10 \mathrm{~mL} / \mathrm{L} \mathrm{NaOH} 40 \% \mathrm{w} / \mathrm{w}$. Samples $(1.5 \mathrm{~mL})$ were injected using an autosampler (model, 838 Advanced Sample Processor, Metrohm, Herisau, Switzerland) and the flow rate through the column was $1 \mathrm{~mL} / \mathrm{min}$, leading to a sampling time (ts) of $38 \mathrm{~min}$. Appropriate dilutions of solutions containing glucose, fructose, sucrose, myo-inositol, D-sorbitol, and D-mannitol (Sigma, Steinheim, Germany) were used as calibration standards. Chromatographic peaks were identified by comparing sample retention times with those of known standard mixtures. The content of these sugars was expressed in milligram per gram fresh weight $(\mathrm{FW})$ 
of the sample and the content of these polyols was expressed in microgram per gram FW. The data were expressed as the mean of three analyses of two different biological replicates. The data were acquired using DataApex Clarity software.

\section{Extraction and Chromatographic Determination of FOS}

Nystose, kestopentaose, and 1-kestose (which required pre-treatment with an activated carbon Darco G60, 100 mesh [Sigma, Steinheim, Germany] to remove the mono- and disaccharides) were quantified according to the method of Blanch et al. (2011). Briefly, the samples were extracted with $85 \%$ ethanol, boiled under reflux, and centrifuged at $5,000 \mathrm{~g}$ for $20 \mathrm{~min}$ at $4{ }^{\circ} \mathrm{C}$. The supernatant was evaporated and the precipitate dissolved in deionized water, filtered through $0.22-\mu \mathrm{m}$ filters and analyzed by HPAEC-PAD using a CarboPac PA1 carbohydrate column. A three-step PAD protocol was employed and the samples $(1.5 \mathrm{~mL})$ were injected using an autosampler (model, 838 Advanced Sample Processor, Metrohm, Herisau, Switzerland). FOS identification was performed by comparing the retention time of standard 1kestose and nystose mixtures from Sigma (Steinheim, Germany), and of kestopentaose from Megazyme (Co. Wicklow, Ireland), and the FOS content was expressed in microgram per gram FW of the sample.

\section{Determination of Water Status and Water Distribution}

The unfreezable (bound) water fraction was determined using a differential scanning calorimeter DSC822e apparatus (Mettler-Toledo Inc., Columbus, OH, USA), according to the method of Goñi et al. (2011). Samples were placed in sealed aluminum pans that were cooled to $-80{ }^{\circ} \mathrm{C}$ at $10{ }^{\circ} \mathrm{C} / \mathrm{min}$, and they were then scanned from -80 to $25{ }^{\circ} \mathrm{C}$ at a rate of $10{ }^{\circ} \mathrm{C} / \mathrm{min}$. The resulting thermograms were evaluated, paying particular attention to the onset temperature and the enthalpy of the melting endotherm from which the quantities of bound water was calculated.

Microstructure was analyzed by low-temperature scanning electron microscopy (LT-SEM), using a Zeiss DSN960 electron scanning microscope equipped with a cold stage (Cryostrans CT-1500, Oxford Instruments, Oxford, UK). Frozen tissue sections were cryofractured at $-180{ }^{\circ} \mathrm{C}$, etched at $-90{ }^{\circ} \mathrm{C}$, gold-coated, and subsequently transferred to the microscope where they were analyzed at -150 to $-160{ }^{\circ} \mathrm{C}$. Samples were observed with both secondary and retro-dispersed electrons, and the best images were selected in each case.
Determination of the Percentage of Air Space and Weight Loss Rate

The percentage air space, as described by Hatfield and Kness (1988), was calculated from the ratio of the fruit density and the density of the juice, according to the equation:

$\operatorname{air} \operatorname{space}(\%)=100 \frac{V_{a}}{V_{F}}=100\left(1-\frac{\rho_{F}}{\rho_{J}}\right)$

Where

$\rho_{\mathrm{F}}=\frac{\mathrm{M}_{\mathrm{F}}}{\mathrm{V}_{\mathrm{F}}}$

and

$\rho_{\mathrm{J}}=\frac{\mathrm{M}_{\mathrm{J}}}{\mathrm{V}_{\mathrm{J}}}=\frac{\mathrm{M}_{\mathrm{F}}}{\mathrm{V}_{\mathrm{F}}-\mathrm{V}_{\mathrm{a}}}$

$\rho_{\mathrm{F}}$ is fruit density, $\rho_{\mathrm{J}}$ is juice density, $\mathrm{M}_{\mathrm{F}}$ is fruit mass, $\mathrm{V}_{\mathrm{F}}$ is fruit volume, $M_{J}$ is juice mass, $V_{J}$ is juice volume, and $V_{a}$ is air volume. The term $\rho_{\mathrm{J}}$ was calculated from the weight of a $1 \mathrm{~mL}$ sample of juice, without achenes, collected in reweighed tips. The density of six individual fruits was measured using a balance with 1-mg sensitivity, placing the whole fruit in a pre-tarred steel mesh fully immersed in a glass container with ethanol. Ethanol instead of water was used to avoid the tendency of water to invade the air spaces when the fruit is immersed.

Strawberry weight loss experiments were carried out with six plastic boxes (lots) containing $0.4 \mathrm{~kg}$ of strawberries per box. Weight of individual lot was recorded initially (day 0 ), just at the end of the treatment period (day 3 ), and 1 day after transfer to air (day 4). Weight loss for each day was calculated for each individual lot as weight percent loss in reference to the initial weight $[100 \times($ initial weight - final weight $) /$ initial weight]. Weight loss rate was expressed as weight loss (\%)/ day.

The surface strawberry color was measured at two different positions around the equator of the fruit, using a Minolta CR200B handheld Chroma Meter (Konica Minolta Sensing Optics, Inc. Osaka, Japan) with an 8-mm diameter measuring area. The total soluble solids were quantified at $20^{\circ} \mathrm{C}$ using a digital refractometer (Atago PR-101, Atago, Japan) and expressed as a percentage. Titratable acidity was determined by titration with $0.1 \mathrm{~N} \mathrm{NaoH}$ to $\mathrm{pH} 8.1$ (Mettler DL-70, Mettler-Toledo, Spain).

Thermal Studies of Aqueous Solutions of Polyols

The amount of unfrozen water $\left(\mathrm{U}_{\mathrm{w}}\right)$, as defined by Furuki (2002), was evaluated calorimetrically on a DSC822e (Mettler-Toledo Inc., Columbus, OH, USA). Aqueous 
solutions of polyol at the desired concentrations were prepared by weighing with deionized distilled water. The polyol concentration was gradually changed from $5 \%$ weight to a maximum of $50 \%$ weight. A series of prepared aqueous solutions were sealed in independent vials and kept for $24 \mathrm{~h}$ at $25{ }^{\circ} \mathrm{C}$ in an incubator to allow them to reach steady state. Aqueous samples $(5$ to $10 \mu \mathrm{L}$ ) were placed in $40-\mu \mathrm{L}$ hermetically sealed aluminum pans and cooled from $25^{\circ} \mathrm{C}$ to $-80^{\circ} \mathrm{C}$ at a rate of $10^{\circ} \mathrm{C} / \mathrm{min}$. The samples were left at this temperature for $5 \mathrm{~min}$ and then heated to $25^{\circ} \mathrm{C}$ at $10{ }^{\circ} \mathrm{C} / \mathrm{min}$. The heating scan was used to determine the latent heat of the melting ice $\left(\Delta \mathrm{H}_{\mathrm{m}}\right)$ by integration of the melting endotherm and the $\mathrm{T}_{\mathrm{g}}$ ' by the deflection midpoint in the heat flow versus temperature curve. $\mathrm{U}_{\mathrm{w}}$ was determined by extrapolating $\Delta \mathrm{H}_{\mathrm{m}}$ to zero, which was linearly dependent on the polyol concentration (weight percent) as expressed below:

$$
U_{w} \frac{\frac{100-C^{\prime} \mathrm{s}}{M_{r}\left(H_{2} O\right)}}{C^{\prime} \mathrm{s}}
$$

where $\mathrm{C}^{\prime} \mathrm{S}$ is the polyol concentration of the freezeconcentrated liquid fraction $\left(\Delta \mathrm{H}_{\mathrm{m}}=0\right)$ expressed in weight percent, $\mathrm{M}_{\mathrm{r}}\left(\mathrm{H}_{2} \mathrm{O}\right)$ the molecular mass of deionized water (18.02 $\mathrm{g} / \mathrm{mol}$ ), and $\mathrm{M}_{\mathrm{r}}$ (polyol) the molecular mass of the different polyols.

\section{Statistical Analysis}

One-way ANOVA and correlational analyses were performed using SPSS ver. 19.0. Multicomparison of means was performed with Tukey's test at a significance level of 0.05 . The main effects of $\mathrm{CO}_{2}$ treatment, storage time, and the treatment/ time interactions on strawberry fruit were analyzed. The data corresponding to the fruit at harvest and the strawberries exposed to the different high $\mathrm{CO}_{2}$ treatments were analyzed by analysis of variance (ANOVA) and a principal component analysis (PCA).

\section{Results and Discussion}

\section{Water Status}

The unfreezable (bound) water content was assessed in strawberries stored at $0{ }^{\circ} \mathrm{C}$ for 3 days in the presence of 0,20 , or $40 \% \mathrm{CO}_{2}$ and after exposure to air for 1 day (Fig. 1). In all the readings, the oxygen concentration was kept at $20 \%$ and any changes were relative to the fruit at harvest (control). There was a significant depletion in the bound water content $(65 \%)$ in $40 \% \mathrm{CO}_{2}$-treated fruit at the end of treatment with respect

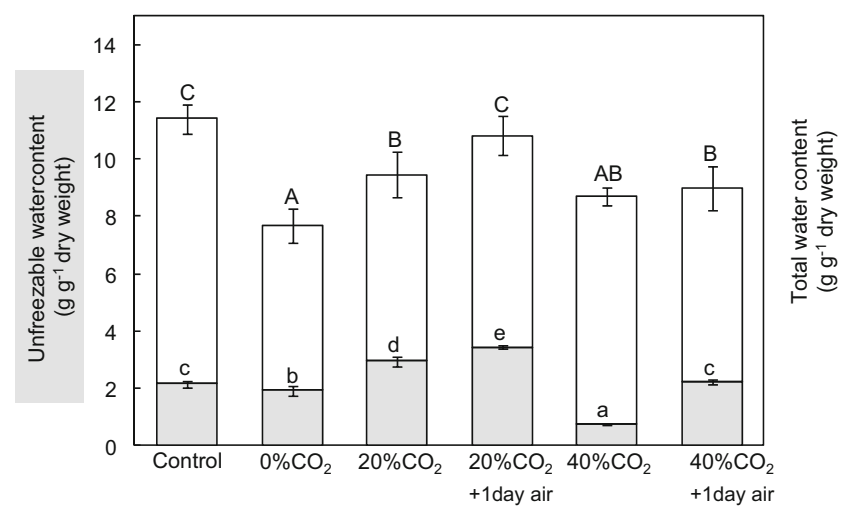

Fig. 1 Changes in the unfreezable (bound) water fraction content (gram per gram dry weight) and in the total water content (gram per gram dry weight) in strawberries at harvest (control), after 3 days of storage at $0{ }^{\circ} \mathrm{C}$ in 0,20 , or $40 \% \mathrm{CO}_{2}$ and 1 day after exposure to air. Dark bars indicate the bound water content. The data are presented as the mean $\pm \mathrm{SE}$ of three replicates $(\mathrm{n}=6)$ and the letters indicate significant differences $(P<0.05)$

to the values in freshly harvested strawberries. However, this decrease in the amount of bound water in $40 \% \mathrm{CO}_{2}$-treated fruit reverted after transfer to air for 1 day. Since the total water content did not decrease (Fig. 1: $40 \% \mathrm{CO}_{2}$ versus $40 \% \mathrm{CO}_{2}+$ 1 day in air), it is clear that the conversion of free water to bound water can be assumed in fruit recovering from excessively high $\mathrm{CO}_{2}$ treatment. There was also less bound water in strawberries stored at $0{ }^{\circ} \mathrm{C}$ with no supplementary $\mathrm{CO}_{2}(0 \%$ $\mathrm{CO}_{2}$ ). Furthermore, in this fruit, the lowest total water content was quantified (Fig. 1). Our results indicate that storage at low temperature without additional $\mathrm{CO}_{2}(0 \%)$ or in the presence of excessive $\mathrm{CO}_{2}(40 \%)$ produced a drop in the bound water fraction content. By contrast, an increase in the bound water fraction was evident at the end of treatment in strawberries maintained in $20 \% \mathrm{CO}_{2}$ and even more so after transfer to air. Changes in the bound water content caused by different environmental factors have been observed in distinct plants (Yoshida et al. 1997; Gusta et al. 2004) and in different tissues of harvested table grape clusters (Goñi et al. 2011). In view of these results, it is reasonable to ask if the changes in water status could be a signal that these concentrations of $\mathrm{CO}_{2}$ induce metabolic responses in fruit during storage, in line with that suggested by Passioura and Munns (2000) for leaves or for the onset of ripening in fruit suggested by Frenkel and Hartman (2012).

\section{Simple Sugars and Polyols}

In order to identify the causes of the variation in the aforementioned water fractions, we analyzed the changes in sugars (sucrose, glucose, and fructose) and their polyol derivatives in strawberries stored at $0{ }^{\circ} \mathrm{C}$ with 0,20 , or $40 \% \mathrm{CO}_{2}$, maintaining a $\mathrm{O}_{2}$ concentration of $20 \%$ in each case (Table 1). The sugar and polyol content was assessed in strawberries at the end of the 3-day treatments and after transfer to air for 1 day. 
Table 1 Sugars (mg/g FW) and polyols ( $\mu \mathrm{g} / \mathrm{g} \mathrm{FW})$ in strawberries Fragaria vesca $\mathrm{cv}$. Mara des Bois at harvest, 3 days of storage at $0{ }^{\circ} \mathrm{C}$ with 0,20 , or $40 \% \mathrm{CO}_{2}$ and after exposure to air for 1 day. In all readings, oxygen concentration was kept at $20 \%$

\begin{tabular}{|c|c|c|c|c|c|c|}
\hline & \multirow{2}{*}{$\begin{array}{l}\text { At harvest } \\
\text { Control }\end{array}$} & \multicolumn{5}{|l|}{ Treatments } \\
\hline & & $0 \% \mathrm{CO}_{2}$ & $20 \% \mathrm{CO}_{2}$ & $20 \% \mathrm{CO}_{2}+1$ day air & $40 \% \mathrm{CO}_{2}$ & $40 \% \mathrm{CO}_{2}+1$ day air \\
\hline \multicolumn{7}{|l|}{ Sugars } \\
\hline Glucose (mg/g FW) & $27.20 \pm 2.2 b$ & $18.74 \pm 1.7 \mathrm{a}$ & $25.39 \pm 1.2 b$ & $22.27 \pm 4.5 \mathrm{ab}$ & $19.36 \pm 2.6 \mathrm{a}$ & $23.56 \pm 0.6 \mathrm{ab}$ \\
\hline Fructose (mg/g FW) & $26.54 \pm 2.6 \mathrm{c}$ & $17.85 \pm 1.8 \mathrm{a}$ & $24.32 \pm 1.4 \mathrm{c}$ & $25.59 \pm 1.9 \mathrm{c}$ & $19.09 \pm 3.0 \mathrm{ab}$ & $23.15 \pm 1.2 \mathrm{bc}$ \\
\hline Sucrose (mg/g FW) & $18.05 \pm 0.6 \mathrm{ab}$ & $13.80 \pm 1.2 \mathrm{a}$ & $19.61 \pm 2.0 \mathrm{~b}$ & $17.67 \pm 1.9 \mathrm{ab}$ & $16.93 \pm 2.6 \mathrm{ab}$ & $18.35 \pm 2.8 \mathrm{ab}$ \\
\hline \multicolumn{7}{|l|}{ Polyols } \\
\hline Myo-inositol ( $\mu \mathrm{g} / \mathrm{g} \mathrm{FW})$ & $581.9 \pm 34.3 \mathrm{~d}$ & $332.3 \pm 17.9 \mathrm{a}$ & $534.2 \pm 39.8 \mathrm{~cd}$ & $436.7 \pm 70.0 \mathrm{bc}$ & $383.8 \pm 58.3 \mathrm{ab}$ & $485.9 \pm 12.2 \mathrm{c}$ \\
\hline Sorbitol ( $\mu \mathrm{g} / \mathrm{g} F W)$ & $35.79 \pm 2.15 b$ & $33.89 \pm 0.9 \mathrm{ab}$ & $42.29 \pm 1.2 \mathrm{c}$ & $32.57 \pm 0.8 \mathrm{ab}$ & $29.67 \pm 2.7 \mathrm{a}$ & $31.97 \pm 1.6 \mathrm{ab}$ \\
\hline Mannitol ( $\mu \mathrm{g} / \mathrm{g} F W)$ & $1.85 \pm 0.2 \mathrm{~b}$ & $2.90 \pm 1.1 \mathrm{c}$ & $2.07 \pm 0.4 \mathrm{~b}$ & $1.27 \pm 0.1 \mathrm{a}$ & $1.41 \pm 0.2 \mathrm{a}$ & $2.11 \pm 0.1 b$ \\
\hline
\end{tabular}

Data are presented as the means SE of three replicates $(\mathrm{n}=6)$ and the different letters within rows indicate significant differences at $P<0.05$

The sucrose concentration was lowest in strawberries stored without added $\mathrm{CO}_{2}$, reaching values of $13.8 \mathrm{mg} / \mathrm{g} \mathrm{FW}, 25 \%$ lower than in freshly harvested fruit (control fruit). In this fruit, the decrease in fructose $(-39 \%)$ or glucose $(-31 \%)$ were the largest changes detected. A marked decrease in glucose and fructose was also quantified in strawberries treated with $40 \%$ $\mathrm{CO}_{2}$. Apart from acting as energy sources and osmoregulators, sugars serve as hydroxyl scavengers in response to oxidative stress and in stabilizing membranes, as well as fulfilling other versatile functions (Couée et al. 2006). Moreover, for glucose and fructose, they serve as a substrate for sorbitol and mannitol, respectively. Compared to reducing sugars, these sugar alcohols are chemically less reactive. The maximum absolute value of these polyols was significantly lower than the levels of myo-inositol, which reached values of $581.9 \mu \mathrm{g} / \mathrm{g} \mathrm{FW}$ at harvest (Table 1). From this initial level, there was a significant decrease in the fruit stored without added $\mathrm{CO}_{2}(43 \%)$, which was milder in $40 \% \mathrm{CO}_{2}$-treated fruit ( $34 \%$ ) and only $8 \%$ in the case of $20 \% \mathrm{CO}_{2}$-treated fruit. The amount of myo-inositol quantified in fruit treated with $40 \% \mathrm{CO}_{2}$ increased significantly after transfer to air, during the recovery from damage induced by the excessive $\mathrm{CO}_{2}$ levels. Our data are consistent with a model in which the possible protection afforded by this cyclitol may protect the fruit from severe storage conditions. Moreover, myo-inositol fulfills important structural and signaling roles in animal and plant cells and in the environment (Irvine 2005), being involved in the phosphate cycle of terrestrial and freshwater ecosystems (Turner et al. 2002), as well as with stress (Loewus and Murthy 2000). The amount of free myo-inositol detected here was significantly higher than that quantified in Fragaria $x$ ananassa cv. Camarosa (Bodelón et al. 2010) or in Fragaria vesca from the first inflorescence (Blanch et al. 2012). Moreover, when comparing carbohydrates during Camarosa growth in two geoclimatic conditions, the only soluble carbohydrate that displayed significant differences between the two locations was inositol (Macías-Rodríguez et al. 2002). Accordingly, it would seem that an interaction with the environment has a direct influence on myo-inositol levels. An effect of growth temperature on myo-inositol levels in several strawberry varieties has also been reported (Wang and Camp 2000) and the data presented above suggests that an interaction with the environment has a direct influence on myo-inositol levels. The presence of sorbitol and/or mannitol follows a strong taxonomical and ecotypic pattern, sorbitol being a major constituent of the leaves and fruit of species from many families, such as Rosaceae (Gao et al. 2003). In Mara des Bois strawberries, the sorbitol content $(35.79 \mu \mathrm{g} / \mathrm{g}$ FW) did not change markedly in the different storage conditions compared to the content in fruit at harvest, with the highest content found in $20 \% \mathrm{CO}_{2}$-treated fruit $(+15 \%)$. The small quantities of mannitol ( $1.8 \mu \mathrm{g} / \mathrm{g} \mathrm{FW})$ only increased in fruit stored without added $\mathrm{CO}_{2}$. Polyol accumulation has been correlated with osmoprotection, serving as a reserve carbon source, as well as promoting protection against salt and photoxidative stress (Williamson et al. 2002; Merchant and Richter 2011). However, their mechanistic role in fruit protection during storage at low temperature remains unclear.

\section{Thermal Study of Aqueous Polyol Solutions}

In order to understand the possible mechanisms by which polyols exert a protective effect, we analyzed the ability of the polyols quantified in strawberries (mannitol, sorbitol, and myo-inositol) to modify the amount of unfrozen water in a mixture of these individual polyols in water. These polyols differ in the number of hydroxyl groups and also in their chemical structure. Alditols, sorbitol, and mannitol are chemically reduced forms of either glucose or fructose, with open chains, while myo-inositol is a cyclic polyol. When the heat of fusion of ice $\left(\mathrm{H}_{\mathrm{f}}\right)$ measured in an aqueous solution of $\mathrm{D}$ sorbitol (A), D-mannitol (B), and myo-inositol (C) was plotted 
against its concentration (weight fraction, weight percent: Fig. 2), the $\mathrm{H}_{\mathrm{f}}$ of the polyols displayed a linear dependence on concentration. In this figure, the $\mathrm{U}_{\mathrm{w}}$ data (according to Furuki 2002) were obtained in terms of moles of water per
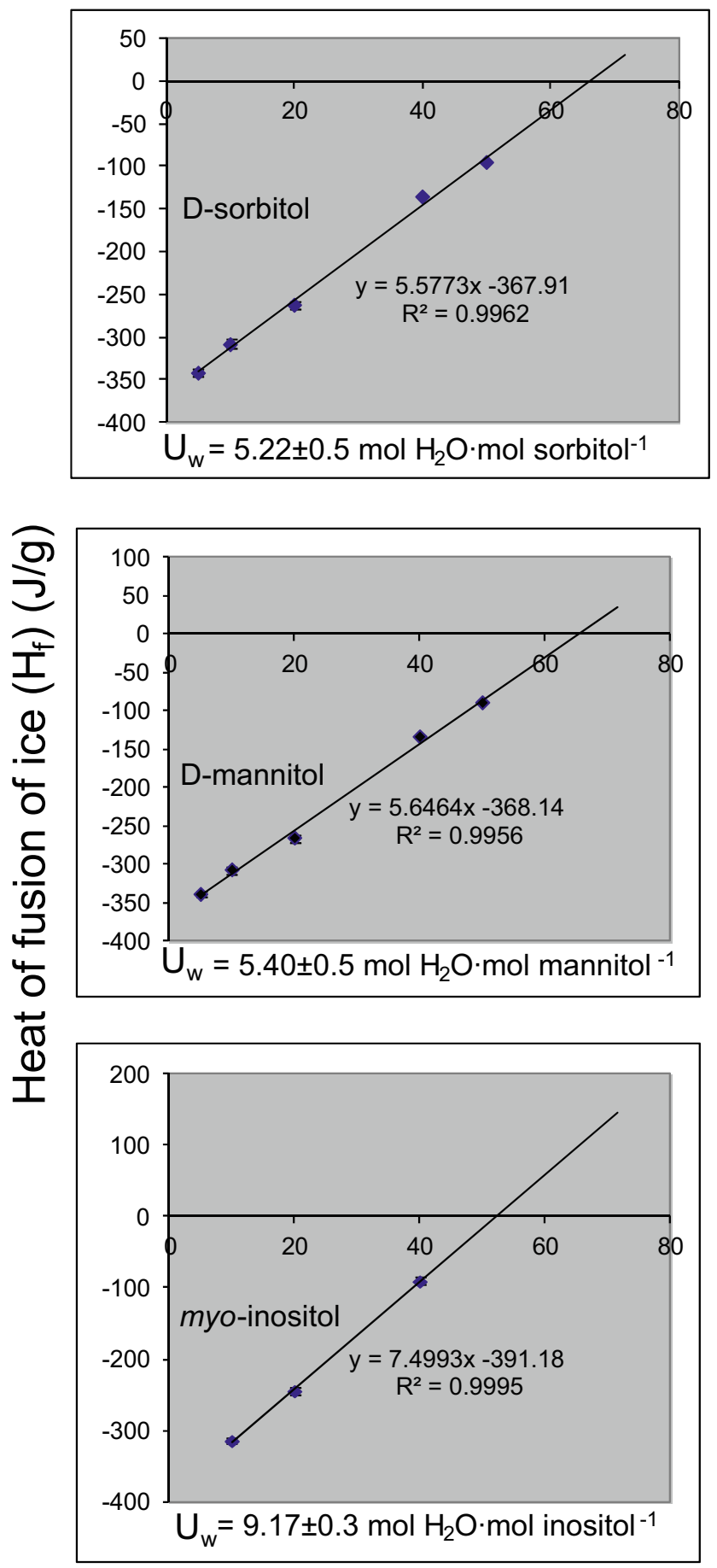

weight fraction, wt, \%

Fig. 2 Relationship between heat of fusion of ice, $H_{\mathrm{f}}$, and the rate of increase in the concentration of D-sorbitol (a), D-mannitol (b), or myoinositol (c), with a correlation coefficient as high as 0.99 for each polyol studied mole solute (Fig. 2). Myo-inositol reached values of $9.1 \mathrm{~mol}$ $\mathrm{H}_{2} \mathrm{O} /$ mol solute, higher than that of sorbitol and mannitol (5.2 and $5.4 \mathrm{~mol} \mathrm{H}_{2} \mathrm{O} / \mathrm{mol}$ solute, respectively), indicating that much more unfrozen water can accumulate in aqueous solutions of myo-inositol. Furthermore, PCA analysis (Fig. 3) performed on the autoscaled data (6 strawberry treatments and 10 variables) and that accounted for $84.29 \%$ of the total variance showed a clear separation between myo-inositol and the other polyols in relation to bound water. So, while myoinositol was located in the positive part of PC1, joined to simple sugars, the third group composed of sorbitol was found in PC3 and there was no addition for mannitol. Regarding the effect of polyols on water, structuring differences between myo-inositol and sorbitol were reported (Politi et al. 2009) despite them having the same number of hydroxyl groups. So, myo-inositol forms no internal hydrogen bonds and creates more interpolyol bonds than sorbitol. Thus, in the context that water ordering decreases in the presence of polyols (Dipaola and Belleau 1977), these compounds may disrupt the surrounding water molecules and thereby restrict the ability of water to adopt a perfect network structure, which could influence cell integrity at aqueous interfaces. Indeed, a water vapor absorption mechanism has been reported in arthropods via accumulation of myo-inositol and glucose (Bayley and Holmstrup 1999), a type of water vapor absorption that confers the capability of meeting the water requirements of a terrestrial arthropod under prolonged drought stress. Although more thermodynamic and structural studies are needed, the present study shows that myo-inositol interferes with water molecules; although this capacity was clearly lower than that of the short-chain FOS (Blanch et al. 2012) but higher than that of sucrose (Furuki 2002 and references therein).

\section{Short-Chain FOS (3-5 Sugar Moieties)}

The profiles of FOS with less than five units were generated from strawberries at the end of treatment with 0,20 , or $40 \%$ $\mathrm{CO}_{2}$ and after exposure to air for 1 day. 1 -Kestose $\left[1^{\mathrm{F}}-(1-\beta-\mathrm{D}-\right.$ fructofuranosylsucrose) $]$, nystose $\left[6^{\mathrm{G}}(1-\beta-\mathrm{D}-\right.$ fructofuranosyl $)_{2}$ sucrose], and kestopentaose $\left[1^{\mathrm{F}}-(1-\beta-\mathrm{D}-\right.$ fructofuranosyl $)_{3}$ sucrose] were identified and quantified by HPAEC-PAD (Table 2). 1-Kestose constitutes the main FOS, reaching values of $84.6 \mu \mathrm{g} / \mathrm{g} \mathrm{FW}$ in freshly harvested fruit, 17 times the next most abundant FOS, nystose. Whereas no significant differences were observed in $20 \% \mathrm{CO}_{2}$-treated fruit with respect to fruit at harvest, the amount of 1-kestose markedly decreased in fruit stored without added $\mathrm{CO}_{2}$ and in $40 \% \mathrm{CO}_{2}$-treated fruit, reaching values of 51.8 and $45.4 \mu \mathrm{g} / \mathrm{g}$ $\mathrm{FW}$, respectively. Interestingly, the levels of 1-kestose in $40 \%$ $\mathrm{CO}_{2}$-treated fruit were restored after exposure to air, with an increase in 1-kestose of $53 \%$. The fructose/1-kestose and sucrose/1-kestose ratio also changed after transfer to air, suggesting that FOS metabolism is affected by high $\mathrm{CO}_{2}$ levels. 
Rotated Component Matrix

\begin{tabular}{|l|r|r|r|}
\hline & \multicolumn{3}{|c|}{ Component } \\
\cline { 2 - 4 } & \multicolumn{1}{|c|}{1} & \multicolumn{1}{c|}{2} & \multicolumn{1}{c|}{3} \\
\hline myo-Inositol (inosit) & .917 & -.109 & .180 \\
Fructose (frut) & .835 & .427 & .247 \\
Glucose (glu) & .829 & .247 & .409 \\
Sucrose (suc) & .718 & .147 & .143 \\
Mannitol (manit) & -.641 & -.359 & .591 \\
Nystose (nyst) & & .935 & -.204 \\
UFW (bound water) & .215 & .835 & .424 \\
Kestose (kest) & .613 & .686 & .168 \\
Sorbitol (sorbit) & .240 & & .828 \\
Kestopentaose & -.306 & -.107 & -.824 \\
\hline kestop)
\end{tabular}

Extraction Method: Principal Component Analysis.

Rotation Method: Varimax with Kaiser Normalization.

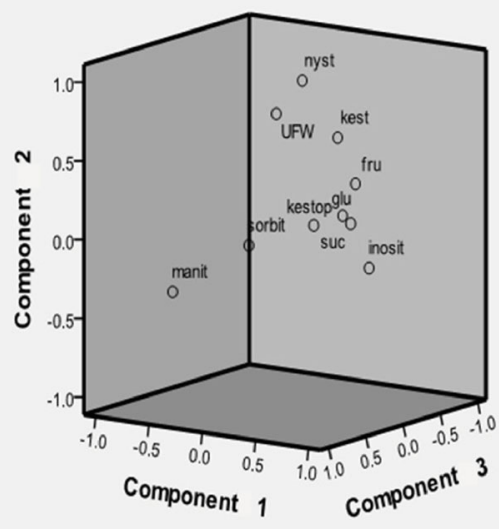

Fig. 3 Three-dimensional diagram of the principal component analysis (PCA) of 6 strawberry treatments and 10 variables. Percentages of the first three principal components (PC1: 37.24; PC2: 24.62; and PC3: 22.44) explained $84.29 \%$ of the total variability

Apart from the well-known health benefits for human, there are many positive aspects related to the presence of fructans in plants (Livingston et al. 2009; McIntyre et al. 2012; Dominguez et al. 2014). They provide protection from the damage caused to cytosolic proteins and cell membranes by severe low temperature (Hoekstra et al. 2001). Indeed, it has been reported that fructans can interact strongly with cell membranes through direct hydrogen bonding with phosphatidylcholine lipid bilayers (Hincha et al. 2000; Vereyken et al. 2001). A previous DSC analysis revealed that 1-kestose, nystose, and kestopentaose exhibit a very high waterbinding capacity, with values of 17.5, 18.9, and $29 \mathrm{~mol}$ $\mathrm{H}_{2} \mathrm{O} /$ mol solute, respectively (Blanch et al. 2012). Furthermore, the aforementioned PCA (Fig. 3) showed that FOS (nystose and 1-kestose) and bound water content are more closely related and they were located in the positive part of PC2. It is reasonable to assume that by reorganizing water network in close proximity to FOS could contribute to the increase in the bound water fraction.

\section{Cellular Integrity, Air Space Percentage, and Weight Loss Rate}

The LT-SEM micrographs of fractured tissues (Fig. 4) revealed an excess of a surrounding aqueous solution in damaged tissues stored at $0{ }^{\circ} \mathrm{C}$ in air (Fig. 4a), that was in part linked to wall disassembly and degradation and in tissues of fruit treated with $40 \% \mathrm{CO}_{2}$ (Fig. 4d). In $40 \% \mathrm{CO}_{2}$-treated fruit, the marked decrease in bound water content (Fig. 1), in part due to the conversion of bound to free water content, could in turn pull water from adjacent cells, thereby generating extra water in the extracellular spaces. However, this excess aqueous solution in tissues treated with $40 \% \mathrm{CO}_{2}$ partially disappeared after transfer to air (Fig. 4e).

Table 2 Fructooligosaccharides (microgram per gram FW) in strawberries Fragaria vesca cv. Mara des Bois at harvest, 3 days of storage at $0{ }^{\circ} \mathrm{C}$ with 0,20 , or $40 \% \mathrm{CO}_{2}$ and after exposure to air for 1 day. In all readings, oxygen concentration was kept at $20 \%$

\begin{tabular}{lllllll}
\hline & At harvest & \multicolumn{2}{l}{ Treatments } & & \\
\cline { 4 - 7 } & Control & $0 \% \mathrm{CO}_{2}$ & $20 \% \mathrm{CO}_{2}$ & $20 \% \mathrm{CO}_{2}+1$ day air & $40 \% \mathrm{CO}_{2}$ & $40 \% \mathrm{CO}_{2}+1$ day air $^{2}$ \\
\cline { 5 - 7 } FOS & & & & & \\
1-Kestose & $84.65 \pm 1.4 \mathrm{~b}$ & $51.88 \pm 4.7 \mathrm{a}$ & $79.27 \pm 2.9 \mathrm{~b}$ & $85.98 \pm 3.4 \mathrm{~b}$ & $45.40 \pm 0.5 \mathrm{a}$ & $79.44 \pm 5.1 \mathrm{~b}$ \\
Nystose & $4.82 \pm 0.1 \mathrm{c}$ & $4.43 \pm 0.5 \mathrm{c}$ & $5.02 \pm 0.2 \mathrm{c}$ & $11.05 \pm 0.6 \mathrm{~d}$ & $3.50 \pm 0.1 \mathrm{~b}$ & $1.29 \pm 0.2 \mathrm{a}$ \\
Kestopentaose & $1.05 \pm 0.1 \mathrm{a}$ & $2.26 \pm 0.5 \mathrm{bc}$ & $1.15 \pm 0.5 \mathrm{ab}$ & $2.54 \pm 0.5 \mathrm{c}$ & $0.82 \pm 0.5 \mathrm{a}$ & $2.92 \pm 0.4 \mathrm{c}$ \\
Fructose/1-kestose & 0.31 & 0.34 & 0.31 & 0.30 & 0.42 & 0.29 \\
Sucrose/1-kestose & 0.21 & 0.26 & 0.25 & 0.20 & 0.38 & 0.23 \\
\hline
\end{tabular}

Data are presented as the means SE of three replicates $(\mathrm{n}=6)$ and the different letters within rows indicate significant differences at $P<0.05$ 
Fig. 4 LTSEM micrographs showing cells of fractured Mara des Bois strawberries after 3 days of storage at $0{ }^{\circ} \mathrm{C}$ in $0 \% \mathrm{CO}_{2}$ (a), in $20 \% \mathrm{CO}_{2}$ (b), and 1 day after transfer to air (c) or in $40 \% \mathrm{CO}_{2}$ (d) and 1 day after transfer to air (e). The extracellular space is indicated by double arrows and the scale bars represent $200 \mu \mathrm{m}$. Inset 1 shows the changes in air space and weight loss percentages of strawberries stored under the different treatments. The data are presented as the mean $\pm \mathrm{SE}$ of three replicates $(n=6)$ and the letters indicate significant differences $(P<0.05)$

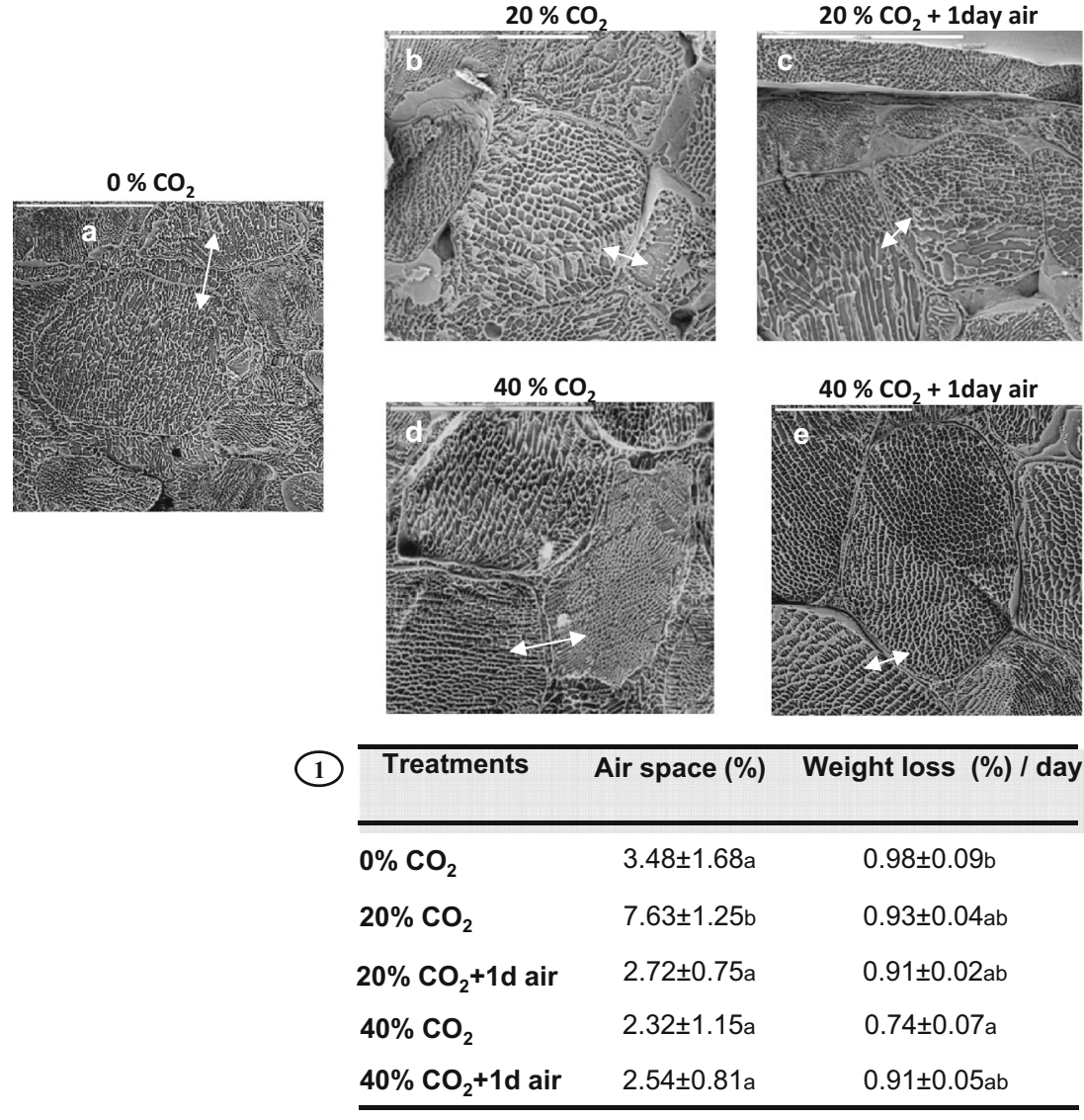

Translucency is a physiological disorder of an unknown cause that occurs when the cell-free spaces become full of liquid, damaging the tissues and giving them a transparent or crystalline aspect. In melon, translucency is diminished by the use of environments rich in $\mathrm{CO}_{2}(15 \mathrm{kPa})$ (Portella and Cantwell 1998). In micrographs of strawberries treated with $20 \% \mathrm{CO}_{2}$, empty intercellular spaces and a well-defined cellular structure was evident at the end of the treatment (Fig. 4b). The structural characteristics visualized were confirmed by our observation that whole fruit treated with $20 \% \mathrm{CO}_{2}$ exhibited the highest percentage of air space at the end of the 3 days of treatment (Fig. 4, inset 1). The effect of $20 \% \mathrm{CO}_{2}$ treatment on the percentage air space in fruit may have implications on gas diffusion as well as on softening process, in line with the reported enhancement of firmness by high-pressure $\mathrm{CO}_{2}$ (Wang et al. 2014). An increase in the air space in the fruit is proposed to lead to easier cell separation and a change in texture (Hatfield and Knee 1988). It is well known that cell separation, which permits spatial displacement of two adjacent cells, is an important event in fruit softening (Roy et al. 1997). Our data showed that the percentage air space observed in $20 \% \mathrm{CO}_{2}$-treated fruit reverted after transfer to air and that this percentage did not increase by increasing the $\mathrm{CO}_{2}$ concentration. In the present study, the effect of increasing $\mathrm{CO}_{2}$ concentrations on weight loss reduction was also showed
(Fig. 4, inset 1). Weight loss rate of fruit decreased as the concentration of $\mathrm{CO}_{2}$ increased. Treatment with $40 \% \mathrm{CO}_{2}$ was associated with the lowest rate of weight loss. When compared with fruit stored without added $\mathrm{CO}_{2}, 40 \% \mathrm{CO}_{2^{-}}$ treated fruit showed a $24 \%$ reduction in the weight loss rate. The extra water in the extracellular spaces may have restrained water loss in these fruits as well as changes in cell-to-cell adhesion. Indeed, it was suggested (Wardlaw 2005) that apoplastic water should not be ignored in plant water studies. According to our results, the $\mathrm{CO}_{2}$ treatment altering the pool of bound water, connected with the availability of reserve carbohydrates, could be modulating the strength of cell adhesion and the physical properties of strawberries.

\section{Conclusions}

Our results show that the decrease in bound water is an important metabolic marked linked to stress and consequently, the re-establishment of initial levels is associated with the ability to recover from unfavorable high $\mathrm{CO}_{2}$ levels. Evidence for the preferential protection afforded by storage in $20 \% \mathrm{CO}_{2}$ was obtained by demonstrating a predominant accumulation of bound water and carbohydrates in such fruit, with a special 
emphasis on 1-kestose and myo-inositol. The ability of these compounds to reorganize water-hydrogen bonding networks might be a key factor involved in the cellular water stabilization. These $\mathrm{CO}_{2}$ driven changes in water status would allow fruit to retain water in the cell more efficiently. Such a beneficial effect is probably more important in the case of highly perishable strawberries.

Acknowledgments This work was financed by the CICYT Project AGL2011-26742. We thank the Hugo Vela nursery for providing certified organic strawberries with requisites in compliance with CE Regulations $834 / 2007$ and 889/2008.

Open Access This article is distributed under the terms of the Creative Commons Attribution License which permits any use, distribution, and reproduction in any medium, provided the original author(s) and the source are credited.

\section{References}

Bayley, M., \& Holmstrup, M. (1999). Water vapor absorption in arthropods by accumulation of myoinositol and glucose. Science, 17, 1909-1911.

Blanch, M., Sanchez-Ballesta, M. T., Escribano, M. I., \& Merodio, C. (2011). Fructooligosaccharides in table grapes and response to storage. Food Chemistry, 129, 724-730.

Blanch, M., Goñi, O., Sanchez-Ballesta, M. T., Escribano, M. I., \& Merodio, C. (2012). Characterization and functionality of fructooligosaccharides affecting water status of strawberry fruit (Fragaria vesca $\mathrm{L}$. cv. Mara des Bois) during postharvest storage. Food Chemistry, 134, 912-919.

Bodelón, O. G., Blanch, M., Sanchez-Ballesta, M. T., Escribano, M. I., \& Merodio, C. (2010). The effects of high $\mathrm{CO}_{2}$ levels on anthocyanin composition, antioxidant activity and soluble sugar content of strawberries stored at low non-freezing temperature. Food Chemistry, 122, 673-678.

Couée, I., Sulmon, C., Gouesbet, G., \& El Amrani, A. (2006). A. Involvement of soluble sugars in reactive oxygen species balance and responses to oxidative stress in plants. Journal of Experimental Botany, 57, 449-459.

Dipaola, G., \& Belleau, B. (1977). Polyol-water interactions. Apparent molal heat capacities and volumes of aqueous polyol solutions. Canadian Journal of Chemistry, 55, 3825-3830.

Dominguez, A. L., Rodrigues, L. R., Lima, N. M., \& Teixeira, J. A. (2014). An overview of the recent developments on fructooligosaccharide production and applications. Food and Bioprocess Technology, 7, 324-337.

Frenkel, C., \& Hartman, T. G. (2012). Decrease in fruit moisture content heralds and might launch the onset of ripening processes. Journal of Food Science, 77, 365-376.

Furuki, T. (2002). Effects of molecular structure on thermodynamic properties of carbohydrates. A calorimetric study of aqueous diand oligosaccharides at subzero temperatures. Carbohydrate Research, 337, 441-450.

Gao, Z., Maurousset, L., Lemoine, R., Yoo, S. D., Van Nocker, S., \& Loescher, W. (2003). Cloning, expression, and characterization of sorbitol transporters form developing sour cherry fruit and leaf sink tissues. Plant Physiology, 131, 1566-1575.

Goñi, O., Muñoz, M., Ruiz-Cabello, J., Escribano, M. I., \& Merodio, C. (2007). Changes in water status of cherimoya fruit during ripening. Postharvest Biology and Technology, 45, 147-150.
Goñi, O., Fernandez-Caballero, C., Sanchez- Ballesta, M. T., Escribano, M. I., \& Merodio, C. (2011). Water status and quality improvement in high- $\mathrm{CO}_{2}$ treated table grapes. Food Chemistry, 128, 34-39.

Gusta, L. V., Wisniewski, M., Nesbitt, N. T., \& Gusta, M. L. (2004). The effect of water, sugars, and proteins on the pattern of ice nucleation and propagation in acclimated and nonacclimated canola leaves. Plant Physiology, 135, 1642-1653.

Hatfield, S. G. S., \& Knee, M. (1988). Effects of water loss on apples in storage. International Journal of Food Science and Technology, 23, $575-583$.

Hincha, D. K., Hellwege, E. M., Heyer, A. G., \& Crowe, J. H. (2000). Plant fructans stabilize phosphatidylcholine liposomes during freeze-drying. European Journal of Biochemistry, 267, 535-540.

Hoekstra, F. A., Golovina, E. A., \& Buitink, J. (2001). Mechanisms of plant desiccation tolerance. Trends in Plant Science, 6, 431-438.

Irvine, R. F. (2005). Inositide evolution-towards turtle domination? Journal Physiology, 566(2), 295-300.

Livingston, D. P., III, Hincha, D. K., \& Heyer, A. G. (2009). Fructan and its relationship to abiotic stress tolerance in plants. Cellular and Molecular Life Sciences, 66, 2007-2023.

Loewus, F. A., \& Murthy, P. P. N. (2000). Myo-inositol metabolism in plants. Plant Science, 150, 1-19.

Macías-Rodríguez, L., Quero, E., \& López, M. G. (2002). Carbohydrate differences in strawberry crowns and fruit (Fragaria $x$ ananassa) during plant development. Journal of Agricultural and Food Chemistry, 50, 3317-3321.

McIntyre, C. L., Seung, D., Casu, R. E., Rebetzke, G. J., Shorter, R., \& Xue, G. P. (2012). Genotypic variation in the accumulation of water soluble carbohydrates in wheat. Functional Plant Biology, 39, 560-568.

Merchant, A., \& Richter, A. A. (2011). Polyols as biomarkers and bioindicators for 21 st century plant breeding. Functional Plant Biology, 38, 934-940.

Passioura, J. B., \& Munns, R. (2000). Rapid environmental changes that affect leaf water status induce transient surges or pauses in leaf expansion rate. Australian Journal of Plant Physiology, 27, 941-948.

Politi, R., Sapir, L., \& Harries, D. (2009). The impact of polyols on water structure in solution: a computational study. The Journal of Physical Chemistry. A, 113, 7548-7555.

Portella, S., \& Cantwell, M. (1998). Quality changes of minimally processed honeydew melons stored in air or controlled atmosphere. Postharvest Biology and Technology, 14, 351-357.

Rascio, A., Russo, M., Platani, C., \& DiFonzo, N. (1998). Drought intensity effects on genotypic differences in tissue affinity for strongly bound water. Plant Science, 132, 29-34.

Roy, S., Watada, A. E., \& Wergin, W. P. (1997). Characterization of the cell wall microdomain surrounding plasmodesmata in apple fruit. Plant Physiology, 114, 539-547.

Sanchez-Ballesta, M. T., Bernardo-Jiménez, J., Romero, I., Orea, J. M., Maldonado, R., González-Ureña, A., Escribano, M. I., \& Merodio, C. (2006). Effect of high $\mathrm{CO}_{2}$ pretreatment on quality, fungal decay and molecular regulation of stilbene phytoalexin biosynthesis in stored table grapes. Postharvest Biology and Technology, 42, 209-216.

Sun, W. Q. (2000). Dielectric relaxation of water-plasticized biomolecules in relation to cellular water organization, cytoplasmic viscosity, and desiccation tolerance in recalcitrant seed tissues. Plant Physiology, 124, 1203-1215.

Turner, B. L., Paphazy, M. J., Haygarth, P. M., \& McKelvie, I. D. (2002). Inositol phosphates in the environment. Philosophical Transactions of the Royal Society B, 357, 449-469.

Valluru, R., \& Van den Ende, W. (2008). Plant fructans in stress environments: emerging concepts and future prospects. Journal of Experimental Botany, 59, 2905-2916. 
Vereyken, I. J., Chupin, V., Demel, R. A., Smeekens, S. C., \& de Kruijff, B. (2001). Fructans insert between the headgroups of phospholipids. Biochimica et Biophysica Acta, 1510, 307-320.

Wang, S. Y., \& Camp, M. J. (2000). Temperatures after bloom affect plant growth and fruit quality of strawberry. Scientia Horticulturae, 85, $183-199$.

Wang, M. H., Kim, J. G., Ahn, S. E., Lee, A. Y., Bae, T. M., Kim, D. R., \& Hwang, Y. S. (2014). Potential role of pectate lyase and $\mathrm{Ca} 2+$ in the increase in strawberry fruit firmness induced by short-term treatment with high-pressure $\mathrm{CO}_{2}$. Journal of Food Science, 79, 685-692.

Wardlaw, I. F. (2005). Consideration of apoplastic water in plant organs: a reminder. Functional Plant Biology, 32, 561-569.
Williamson, J. D., Jennings, D. B., Guo, W.-W., Pharr, D. M., \& Ehrenshaft, M. (2002). Sugar alcohols, salt stress, and fungal resistance: polyols-multifunctional plant protection? Journal of the American Society for Horticultural Science, 127, 467-473.

Wolfe, J., Bryant, G., \& Koster, K. L. (2002). What is 'unfreezable water', how unfreezable is it and how much is there? CryoLetters, 23, 157166.

Yoshida, M., Abe, J., Moriyama, M., Shimokawa, S., \& Nakamura, Y. (1997). Seasonal changes in the physical state of crown water associated with freezing tolerance in winter wheat. Physiologia Plantarum, 99, 363-370. 